\title{
Mixing Time in a Bath in the Presence of Swirl Motion Induced by Horizontal Gas Injection with an L-Shaped Lance
}

\author{
Norifumi KOCHI, ${ }^{1)}$ Koji MORI, ${ }^{2)}$ Yasushi SASAKI') and Manabu IGUCHI ${ }^{1)}$ \\ 1) Division of Materials Science and Engineering, Graduate School of Engineering, Hokkaido University, Nishi 8, Kita 13, Kita- \\ ku, Sapporo, Hokkaido 060-8628 Japan. $\quad$ 2) Graduate School of Engineering, Osaka Electro-Communication University, \\ 18-8 Hatsu-cho, Neyagawa, Osaka 572-8530 Japan. $\quad 3)$ Graduate Institute of Ferrous Technology, Pohang University of \\ Science and Technology, San 31, Hyoja-Dong, Nam-Gu, Pohang, 790-784 Korea (South).
}

(Received on November 2, 2010; accepted on November 26, 2010)

\begin{abstract}
Water model experiments are carried out to understand the mixing behavior of the steel refining processes agitated by horizontal gas injection. Mixing time in a cylindrical water bath agitated by horizontal air injection through an L-shaped top lance is measured with an electric conductivity meter. Several types of bath surface oscillations are induced by the gas injection depending on the operation parameters such as the vessel diameter and gas flow rate. Particular emphasis is placed on the condition that a swirl motion of the deep-water wave type appears in the bath. This is because the swirl motion plays a practically important role for bath mixing. The diameter of the bath, lance exit position, bath depth, and gas flow rate are varied over a wide range. An empirical equation is proposed for the mixing time in the presence of the swirl motion.
\end{abstract}

KEY WORDS: steelmaking; gas injection; AOD process; swirl motion; mixing time.

\section{Introduction}

Horizontal gas injection is commonly utilized in the stainless steel refining processes such as the AOD process. ${ }^{1-4)}$ The mixing behavior of the molten metal bath in the reactor however is not fully understood yet. The authors have been investigating the fluid flow phenomena agitated by horizontal gas injection to enhance the mixing efficiency of the current refining processes as well as to develop novel refining processes. ${ }^{4-8)}$ In previous water model studies, experiments were carried out on the bath surface oscillations induced by horizontal air injection into a cylindrical water bath through an L-shaped lance. ${ }^{9-12)}$ Several kinds of bath surface oscillations were observed depending on the diameter of the vessel, $D$, gas flow rate, $Q_{\mathrm{g}}$, bath depth, $H_{\mathrm{L}}$, and the lance immersion depth, $H_{\text {in }}$. A map was drawn as a function of the dimensionless lance immersion depth, $H_{\text {in }} / D$, and gas flow rate, $Q_{\mathrm{g}}$, to identify the occurrence conditions of the oscillations. ${ }^{12)}$ Particular attention was paid to the swirl motion of the deep-water wave type because of its practical importance. ${ }^{13,14)}$ Empirical equations were proposed to describe the boundary of the occurrence region of the swirl motion on the map. ${ }^{12)}$ The measured values of the period, $T_{\mathrm{s}}$, and amplitude, $A$, of the swirl motion were compared favorably with previously proposed empirical equations for the bottom gas injection.

In this study the mixing time was experimentally measured in the presence of the swirl motion of the deep-water wave type to derive an empirical equation for itself.

\section{Experiment}

Figure 1 shows a schematic of the experimental apparatus. Two vessels of the diameters of $D=0.130 \mathrm{~m}$ and $0.200 \mathrm{~m}$ were used. De-ionized water and air were chosen as the model working fluids for molten steel and argon, respectively. Air was injected into the water bath from an Lshaped lance in the horizontal direction. The inner and outer diameters of the lance, $d_{\mathrm{ni}}$ and $d_{\text {no }}$, were $3.7 \mathrm{~mm}$ and $5.1 \mathrm{~mm}$ for $D=0.130 \mathrm{~m}$, and $4.1 \mathrm{~mm}$ and $6.4 \mathrm{~mm}$ for $D=$ $0.200 \mathrm{~m}$, respectively. The exit of the lance was placed on the centerline of the vessel and its stem was located at $r=R / 2$. Here, $r$ is the radial distance and $R$ is the vessel radius. The gas flow rate, $Q_{\mathrm{g}}$, was adjusted with a mass flow controller over a wide range. Bath surface oscillations were observed by eye inspection and with a high-speed camera.

The mixing time was measured with an electric conductivity meter. $\mathrm{A} \mathrm{KCl}$ aqueous solution of $1 \mathrm{~mol} / \mathrm{L}$ was used as a tracer liquid. A top view of the probe and tracer charge positions are shown in Fig. 2 together with the electrical conductivity change with time. The tip of the probe is located $20 \mathrm{~mm}$ from the bottom wall and $10 \mathrm{~mm}$ from the side wall, just as in the previous study. The aqueous $\mathrm{KCl}$ solution was charged onto the bath surface using a small beaker. The volume of the tracer was chosen to be $0.1 \mathrm{vol} \%$ of bath water. The mixing time was defined as the period from the instance of tracer charge to the moment at which the electric conductivity settles down between $95 \%$ and $105 \%$ of its final value, as shown in Fig. 2. Namely, the so-called $\pm 5 \%$ criterion was chosen in this study. Mixing time measurements were repeated three times under every experimental condition. 


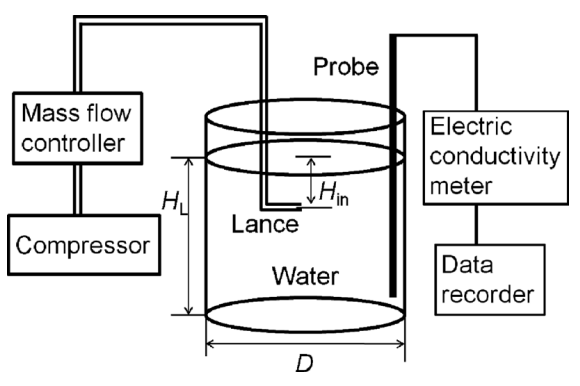

Fig. 1. Experimental apparatus.
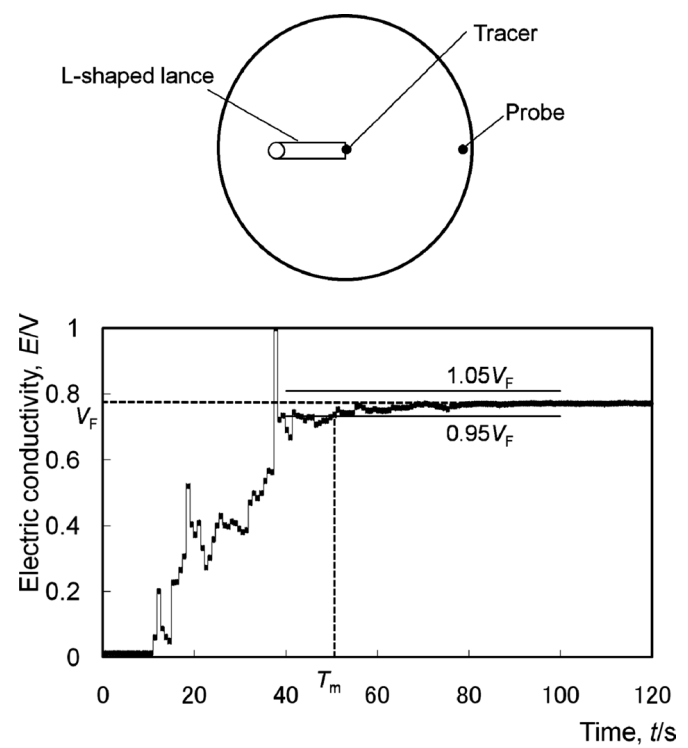

Fig. 2. Tracer charge position and probe position, and definition of mixing time.

\section{Experimental Results and Discussion}

\subsection{Occurrence Condition of Steady Swirl Motion of the Deep-water Wave Type}

3.1.1. Derivation of Empirical Equations Describing Occurrence Condition

Swirl motions of a bubbling jet induced by the horizontal gas injection can be classified into two categories, shallowwater and deep-water wave types, ${ }^{12)}$ mainly depending on the dimensionless lance immersion depth, $H_{\text {in }} / D$. The former appears for $H_{\text {in }} / D$ smaller than about 0.3 , while the latter appears for $H_{\mathrm{in}} / D$ greater than about 0.3 . In the presence of the swirl motion of the deep-water wave type, the buoyancy forces acting on bubbles generated in the bath are effectively transferred to liquid in the bath to circulate the liquid unlike the case of the swirl motion of the shallow-water wave type. ${ }^{13)}$ Accordingly, the bath is more effectively agitated by the swirl motion of the deep-water wave type than by the swirl motion of the shallow-water wave type.

The swirl motion of the deep-water wave type sometimes stopped for a while and then recovered under a certain blowing condition. These events were nearly periodically repeated. This type of swirl motion was named an intermittent swirl motion and excluded from the analysis. Accordingly, only a steady swirl motion of the deep-water wave type was treated in this study.

A snapshot of the bath in the presence of the steady swirl

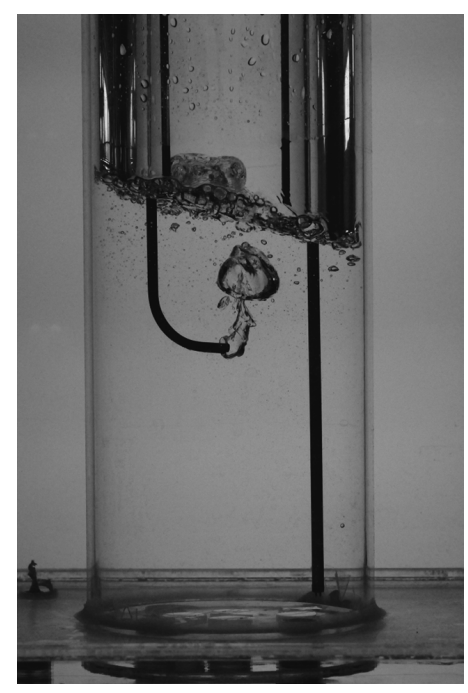

Fig. 3. Snap shot of a water bath in the presence of a deep-water wave type of swirl motion $\left(D=0.130 \mathrm{~m}, Q_{\mathrm{g}}=2.00 \times 10^{-4}\right.$ $\mathrm{m}^{3} / \mathrm{s}, H_{\mathrm{L}} / D=1.5$ and $\left.H_{\mathrm{in}} / D=0.5\right)$.

motion of the deep-water wave type is shown in Fig. 3. The vessel diameter, $D$, was $0.130 \mathrm{~m}$, the gas flow rate, $Q_{\mathrm{g}}$, was $2.00 \times 10^{-4} \mathrm{~m}^{3} / \mathrm{s}$, the bath depth, $H_{\mathrm{L}}$, was $0.195 \mathrm{~m}\left(H_{\mathrm{L}} / D=\right.$ $1.5)$, and the dimensionless lance immersion depth, $H_{\text {in }} / D$, was 0.5 . The period, $T$, and the amplitude, $A$, of the swirl motion were $0.388 \mathrm{~s}$ and $0.015 \mathrm{~m}$, respectively.

First, the occurrence condition of the swirl motion of the deep-water wave type will be discussed below. In the previous study ${ }^{12)}$ an oscillation pattern map was introduced to identify the occurrence condition of the steady and intermittent swirl motions of the deep-water wave type. The following three empirical equations were proposed for describing the boundary of the occurrence region of the swirl motions on the map.

(1) Sub-boundary (I)

$$
\begin{gathered}
\left(H_{\mathrm{in}}+0.15 D\right) / D=0.19 \mathrm{Fr}_{\mathrm{mD}}^{-1 / 20} \\
\mathrm{Fr}_{\mathrm{mD}}=Q_{\mathrm{g}}^{2} /\left(g D^{5}\right) \ldots \ldots \ldots \ldots
\end{gathered}
$$

where $\mathrm{Fr}_{\mathrm{mD}}$ is the modified Froude number and $g$ is the acceleration due to gravity. Equation (1) is applicable to this case without any modifications.

(2) Sub-boundary (II)

$$
\begin{array}{r}
\left(H_{\mathrm{in}}+0.15 D\right) / D=(1.0+0.3 \log \mathrm{We})^{1 / 2} \\
\mathrm{We}=\rho_{\mathrm{L}} Q_{\mathrm{g}}^{2} /\left(\sigma D^{3}\right) \ldots \ldots \ldots \ldots \ldots \ldots \ldots \ldots \ldots \ldots \ldots \ldots
\end{array}
$$

where We is the modified Weber number, $\rho_{\mathrm{L}}$ is the density of liquid, and $\sigma$ is the surface tension. Equation (3) also is applicable to this case without any modifications.

(3) Sub-boundary (III)

$$
\begin{array}{r}
H_{\text {in }} / D=1.09-3.7 k_{2} d_{\mathrm{ni}} \mathrm{Fr}_{\mathrm{m}}^{1 / 3} / D \\
\mathrm{Fr}_{\mathrm{m}}=\rho_{\mathrm{g}} Q_{\mathrm{g}}^{2} /\left(\rho_{\mathrm{L}} g d_{\mathrm{ni}}^{5}\right) \ldots \ldots \ldots
\end{array}
$$

where $d_{\mathrm{ni}}$ is the inner diameter of the lance and $\mathrm{Fr}_{\mathrm{m}}$ is another type of modified Froude number applicable to describing the flow field near the lance exit. The fitting parameter, $k_{2}$, for the occurrence region of steady and inter- 
mittent swirl motions of the deep-water wave type was found in the previous study as:

$$
k_{2}=2.0
$$

Accordingly, substituting Eq. (7) into Eq. (5) yields

$$
H_{\text {in }} / D=1.09-7.4 d_{\text {ni }} \operatorname{Fr}_{\mathrm{m}}^{1 / 3} / D
$$

The coefficient, $k_{2}$, was modified to fit the boundary of the occurrence region of the steady swirl motion. The value of $k_{2}$ thus determined in this study was 3.0. Substituting $k_{2}=3.0$ into Eq. (5) gives

$$
H_{\text {in }} / D=1.09-11.1 d_{\mathrm{ni}} \mathrm{Fr}_{\mathrm{m}}^{1 / 3} / D
$$

The physical backgrounds for deriving Eqs. (1), (3), and (5) should be referred to Ref. 12).

Figures 4 through 9 show the oscillation pattern maps for the different two vessel diameters. The steady swirl motion of the deep-water wave type was denoted by an open circle, $\bigcirc$. The remaining types including the intermittent swirl motion of the deep-water wave type were collectively denoted by $\times$. Equations (1), (3), and (9) were drawn with solid lines in each figure. It is evident that the boundary can be satisfactorily approximated by these three empirical equations. Meanwhile, these equations do not include the effect of bath depth, $H_{\mathrm{L}}$. This is because the swirl motion of the deep-water wave type is not affected by the bottom wall of the vessel. Mixing time measurements were carried out in the presence of a steady swirl motion of the deep-water wave type.

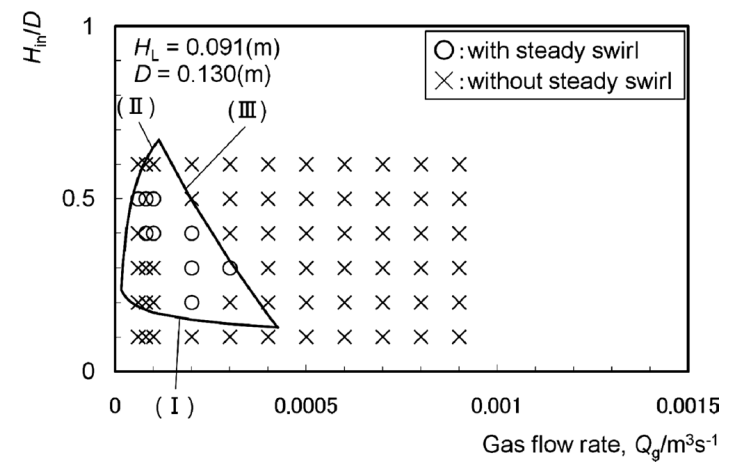

Fig. 4. Oscillation pattern map for identifying the occurrence region of a swirl motion of the deep-water wave type $(D=$ $0.130 \mathrm{~m}$ and $\left.H_{\mathrm{L}}=0.091 \mathrm{~m}\right)$.

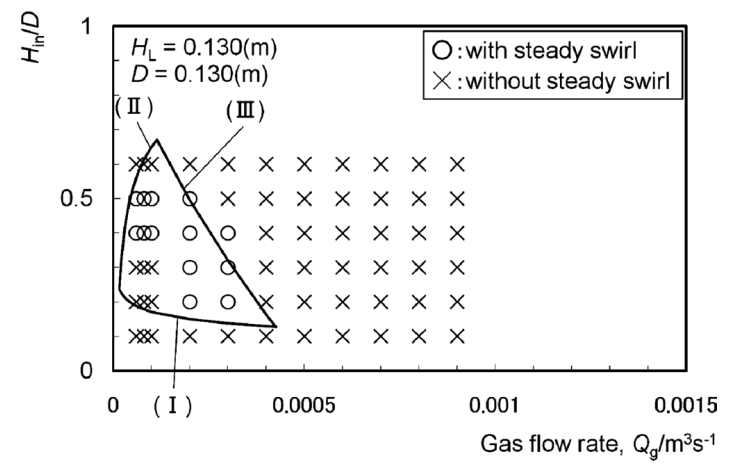

Fig. 5. Oscillation pattern map for identifying the occurrence region of a swirl motion of the deep-water wave type $(D=$ $0.130 \mathrm{~m}$ and $\left.H_{\mathrm{L}}=0.130 \mathrm{~m}\right)$.

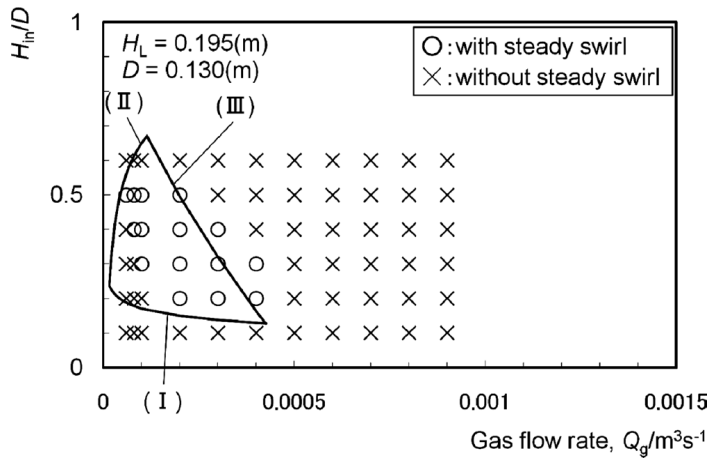

Fig. 6. Oscillation pattern map for identifying the occurrence region of a swirl motion of the deep-water wave type $(D=$ $0.130 \mathrm{~m}$ and $H_{\mathrm{L}}=0.195 \mathrm{~m}$ ).

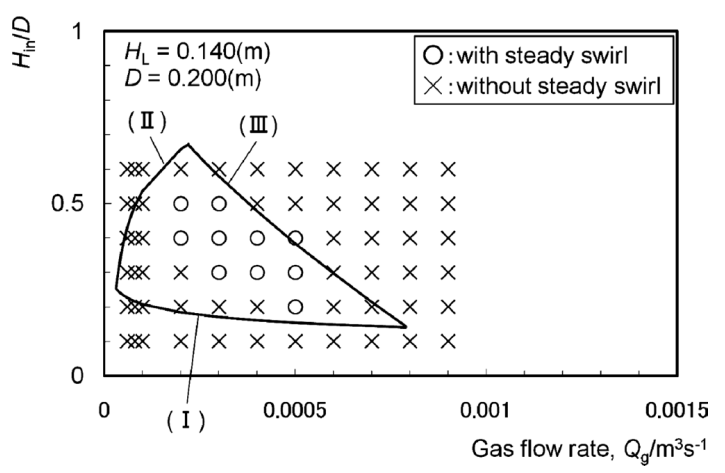

Fig. 7. Oscillation pattern map for identifying the occurrence region of a swirl motion of the deep-water wave type $(D=$ $0.200 \mathrm{~m}$ and $H_{\mathrm{L}}=0.140 \mathrm{~m}$ ).

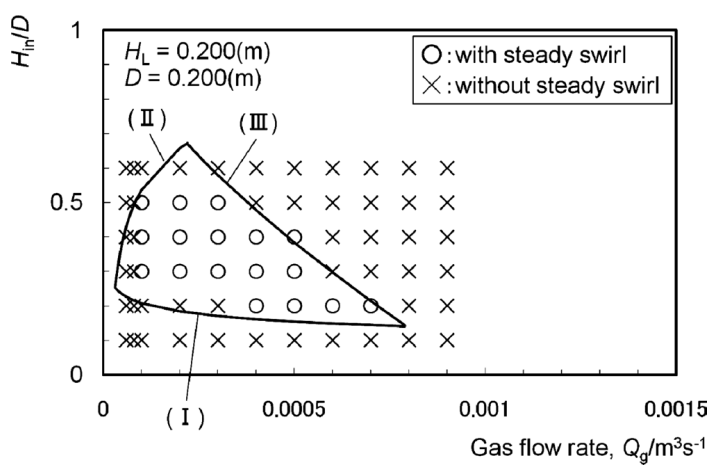

Fig. 8. Oscillation pattern map for identifying the occurrence region of a swirl motion of the deep-water wave type $(D=$ $0.200 \mathrm{~m}$ and $H_{\mathrm{L}}=0.200 \mathrm{~m}$ ).

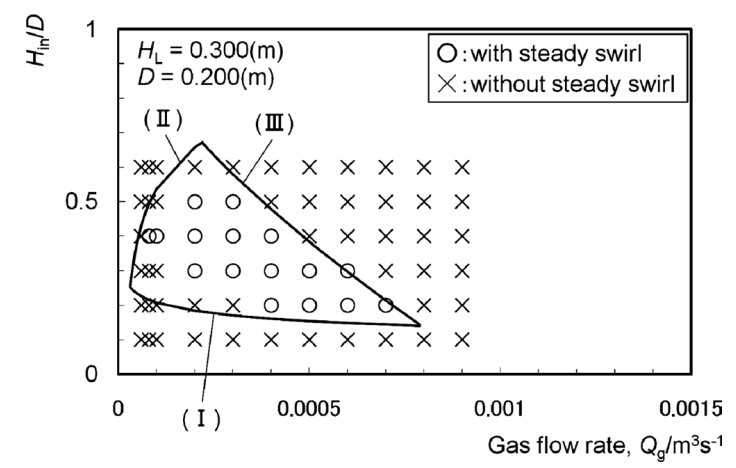

Fig. 9. Oscillation pattern map for identifying the occurrence region of a swirl motion of the deep-water wave type $(D=$ $0.200 \mathrm{~m}$ and $H_{\mathrm{L}}=0.300 \mathrm{~m}$ ). 


\subsubsection{Applicability of Presently Derived Empirical Equa- tions to Molten Metal Bath}

According to previous investigations on the swirl motion of the deep-water wave type in a molten metal bath agitated by bottom gas injection, ${ }^{13)}$ the occurrence condition of the swirl motion can be described by empirical equations derived from water model experiments. This is because the bubble dispersion behavior in a molten metal is similar to that in a water bath, as gas is injected straight upwards in the bath. In the horizontal gas injection, however, the horizontal penetration depth of bubbles would be different from that in a water bath. The horizontal penetration depth is closely associated with the sub-boundary (III). Consequently, the applicability of Eq. (9) to a molten metal bath must be left for a future study. Equations (1) and (3) have nothing to do with the horizontal penetration depth and, hence, seem to be useful also in a molten metal bath.

\subsection{Mixing Time}

3.2.1. Relationship between Mixing Time, $T_{\mathrm{m}}$, and Gas Flow Rate, $Q_{\mathrm{g}}$

Figure 10 shows the measured values of mixing time, $T_{\mathrm{m}}$, against gas flow rate, $Q_{\mathrm{g}}$, for $D=0.130 \mathrm{~m}$. The aspect ratio of the bath was denoted by $H_{\mathrm{L}} / D$, where $H_{\mathrm{L}}$ is the initial bath depth, i.e., bath depth before gas injection. The measured value of $T_{\mathrm{m}}$ decreased monotonically with an increase in $Q_{\mathrm{g}}$. It is well known that the mixing time in a bottom blown bath is proportional to $Q_{\mathrm{g}}^{-0.47} \cdot{ }^{15)}$ The index of -0.47 was indicated by the gradient of the triangle in Fig. 10 . The measured value of $T_{\mathrm{m}}$ decreased nearly proportional to $Q_{\mathrm{g}}^{-0.47}$ for every aspect ratio. The same tendency was observed for the vessel of $D=0.200 \mathrm{~m}$, as can be seen in Fig. 11.

\subsubsection{Relationship between Mixing Time, $T_{\mathrm{m}}$, and Lance Immersion Depth, $H_{\text {in }}$}

As shown above, the dependency of the mixing time, $T_{\mathrm{m}}$, on the gas flow rate, $Q_{\mathrm{g}}$, observed in this study was the same as that reported for the bottom blown bath. ${ }^{15}$

$$
T_{\mathrm{m}} \propto Q_{\mathrm{g}}^{-0.47}
$$

Accordingly, one of empirical equations for $T_{\mathrm{m}}$ originally proposed for the bottom blown bath was referred to derive an empirical equation for $T_{\mathrm{m}}$ applicable to the horizontal gas injection.

The empirical equation for $T_{\mathrm{m}}$ for a bottom blown bath is expressed by

$$
\begin{gathered}
T_{\mathrm{m}}\left(H_{\mathrm{L}} / D\right)(g / D)^{1 / 2}=4.21 \times 10^{3} \mathrm{Re}^{-0.47} \\
\operatorname{Re}=v_{\mathrm{sp}} D / v_{\mathrm{L}} \ldots \ldots \ldots \ldots \ldots \ldots \ldots \ldots \ldots \ldots \ldots \ldots \ldots \ldots \ldots \ldots \\
v_{\mathrm{sp}}=4 Q_{\mathrm{g}} /\left(\pi D^{2}\right)
\end{gathered}
$$

where $g$ is the acceleration due to gravity, Re is the Reynolds number, $v_{\mathrm{sp}}$ is the superficial velocity of gas, and $v_{\mathrm{L}}$ is the kinematic viscosity of liquid.

The measured values of $T_{\mathrm{m}}$ were non-dimensionalized by referring to Eq. (11) and plotted against $H_{\text {in }} / H_{\mathrm{L}}$ for different three aspect ratios in Fig. 12. The vessel diameter, $D$, was $0.130 \mathrm{~m}$. The mixing time thus non-dimensionalized was

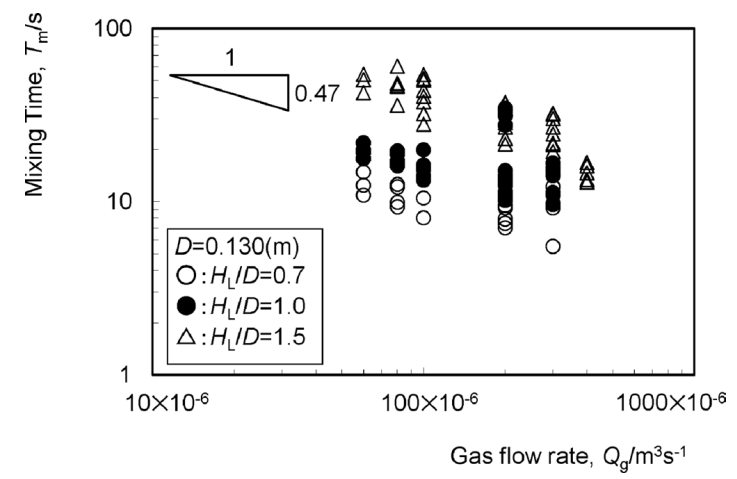

Fig. 10. Relationship between mixing time and gas flow rate $(D=0.130 \mathrm{~m})$.

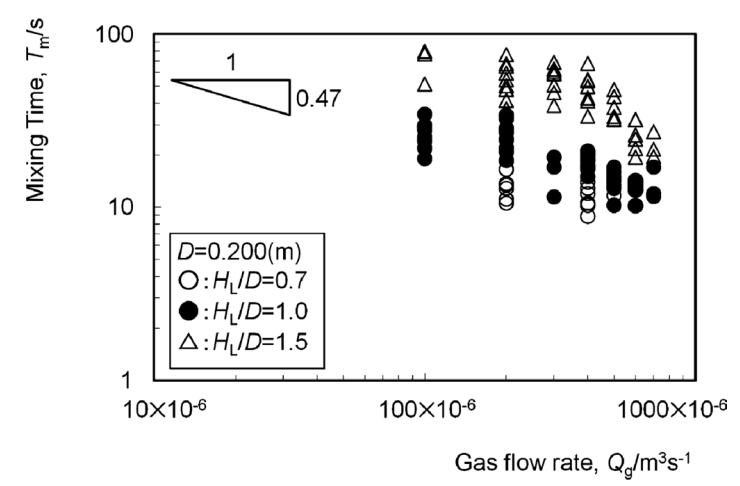

Fig. 11. Relationship between mixing time and gas flow rate $(D=0.200 \mathrm{~m})$.

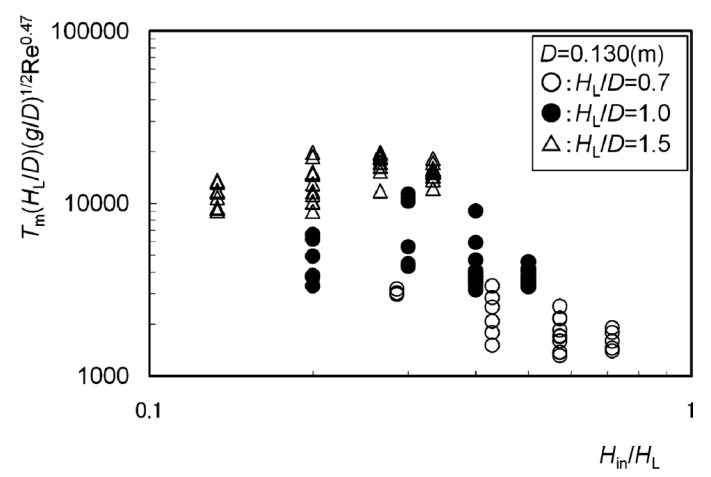

Fig. 12. Relationship between dimensionless mixing time and dimensionless lance immersion depth $(D=0.130 \mathrm{~m})$.

not dependent on the dimensionless lance immersion depth, $H_{\text {in }} / H_{\mathrm{L}}$, for every aspect ratio, $H_{\mathrm{L}} / D$. Figure 13 indicates the same tendency as that for $D=0.200 \mathrm{~m}$.

\subsubsection{Relationship between Mixing Time, $T_{\mathrm{m}}$, and Bath Depth, $H_{\mathrm{L}}$}

Figures 12 and 13 collectively mean that the mixing time, $T_{\mathrm{m}}$, is still dependent on the aspect ratio, $H_{\mathrm{L}} / D$. All the measured values of $T_{\mathrm{m}}$ therefore were replotted in Fig. 14. This figure suggests that Eq. (11) should be modified as follows:

$$
T_{\mathrm{m}}\left(H_{\mathrm{L}} / D\right)(g / D)^{1 / 2}=m\left(H_{\mathrm{L}} / D\right)^{n} \mathrm{Re}^{-0.47}
$$

where the coefficient, $m$, and the index, $n$, are assumed to be constant. 


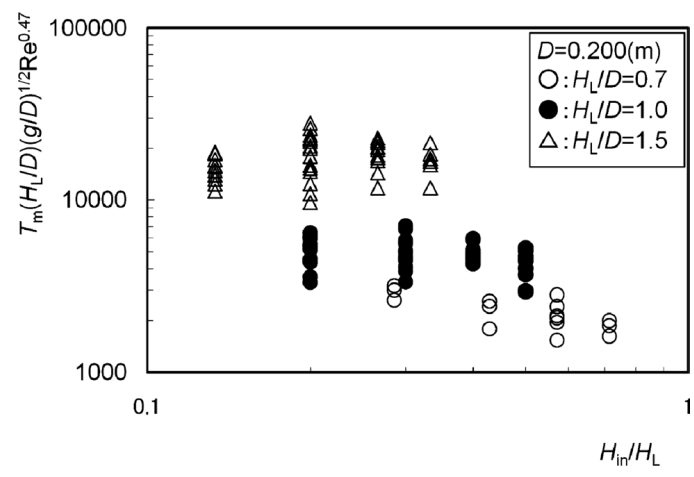

Fig. 13. Relationship between dimensionless mixing time and dimensionless lance immersion depth $(D=0.200 \mathrm{~m})$.

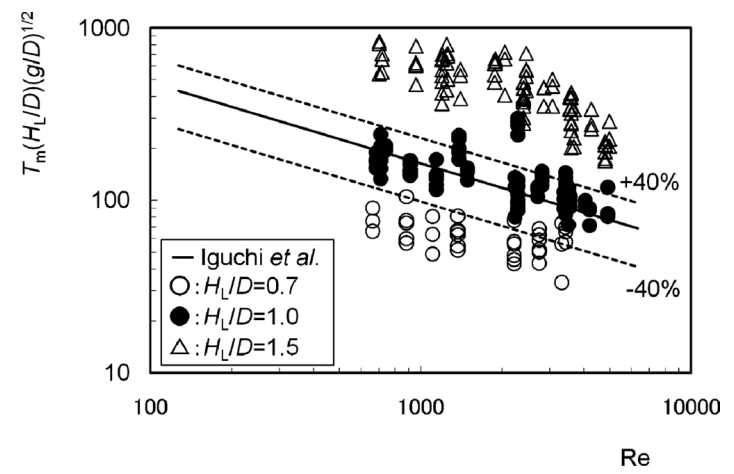

Fig. 14. Relationship between dimensionless mixing time and Reynolds number.

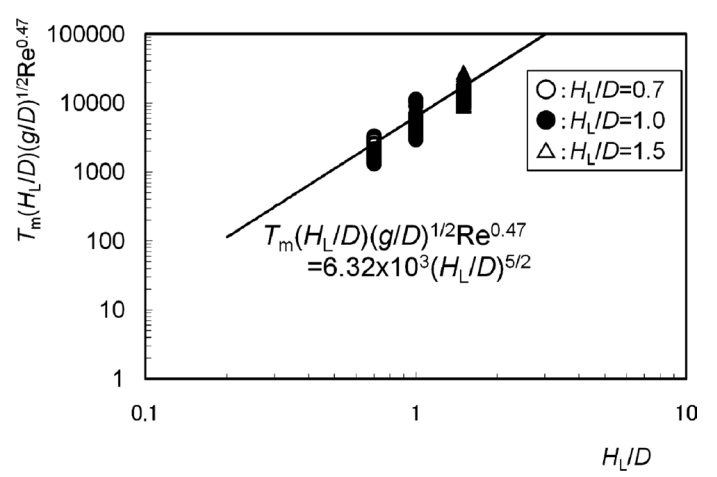

Fig. 15. Relationship between dimensionless mixing time and aspect ratio.

The measured values shown in Fig. 14 were further plotted against the aspect ratio, $H_{\mathrm{L}} / D$, in Fig. 15 to determine the coefficient, $m$, and the index, $n$. The following empirical equation was finally derived.

$$
\begin{gathered}
T_{\mathrm{m}}\left(H_{\mathrm{L}} / D\right)(g / D)^{1 / 2} \\
=6.32 \times 10^{3}\left(H_{\mathrm{L}} / D\right)^{5 / 2} \mathrm{Re}^{-0.47} \\
\left(0.7 \leq H_{\mathrm{L}} / D \leq 1.5,0.2<H_{\text {in }} / D<0.5,588<\operatorname{Re}<4460\right)
\end{gathered}
$$

The measured values of $T_{\mathrm{m}}$ for $D=0.130 \mathrm{~m}$ are plotted in Fig. 16 in order to more clearly check the adequacy of Eq. (15). Equation (15) can approximate the measured values within a scatter of $\pm 50 \%$. The same degree of agreement

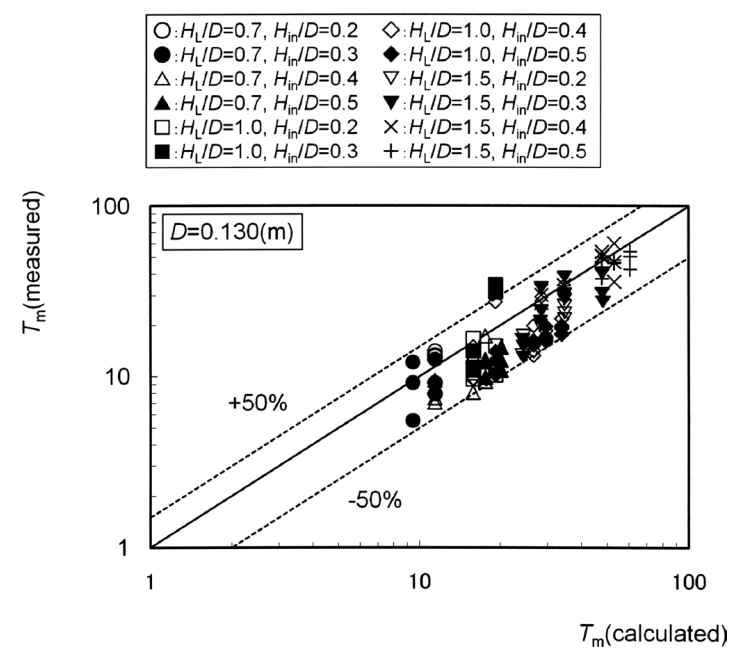

Fig. 16. Comparison of measured with calculated mixing time values for $D=0.130 \mathrm{~m}$.

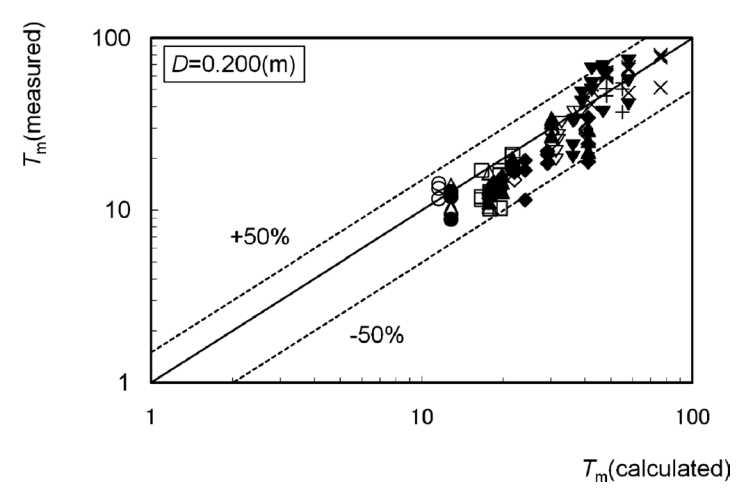

Fig. 17. Comparison of measured with calculated mixing time values for $D=0.200 \mathrm{~m}$ (Key: same as in Fig. 16).

can be seen for $D=0.200 \mathrm{~m}$ in Fig. 17. Such a degree of scatter is acceptable in this kind of experiment.

Applicability of Eq. (15) to a molten metal bath agitated by horizontal gas injection through an L-shaped lance also must be left for a future study.

\section{Conclusions}

Water model experiments were carried out to understand the mixing time for a bath agitated by horizontal gas injection through an L-shaped top lance. Particular attention was paid to the mixing behavior of the bath in the presence of the swirl motion of the deep-water wave type. This is because strong mixing is expected when the swirl motion appears. Main findings obtained in this study can be summarized as follows:

(1) The region where the steady swirl motion of the deep-water wave type appears in the bath was shown on the flow pattern map. Three empirical Eqs. (1), (3) and (9), were proposed for describing the boundary of the abovementioned region.

(2) The following empirical equation was proposed for the mixing time of the bath in the presence of the steady swirl motion of the deep-water wave type. 
ISIJ International, Vol. 51 (2011), No. 3

$$
\begin{aligned}
& T_{\mathrm{m}}\left(H_{\mathrm{L}} / D\right)(g / D)^{1 / 2} \\
& \quad=6.32 \times 10^{3}\left(H_{\mathrm{L}} / D\right)^{5 / 2} \mathrm{Re}^{-0.47}
\end{aligned}
$$

$\left(0.7 \leq H_{\mathrm{L}} / D \leq 1.5,0.2<H_{\text {in }} / D<0.5,588<\operatorname{Re}<4460\right)$

\section{REFERENCES}

1) Y. Sahai and G. R. St. Pierre: Advances in Transport Processes in Metallurgical Systems, Elsevier, Amsterdam, (1992).

2) G. Mazumdar and R. I. L. Guthrie: ISIJ Int., 35 (1995), No. 1, 1.

3) N. J. Themelis, P. Tarasoff and J. Szekely: Trans. Metall. Soc. AIME, 245 (1969), 2425.

4) M.-Y. Zhu, I. Sawada and M. Iguchi: ISIJ Int., 38 (1998), 411.

5) M. Iguchi, S. Kodani and H. Tokunaga: Steel Res., 71 (2000), No. $11,435$.

6) T. Sato, M. Bujrström, P. Jönsson and M. Iguchi: ISIJ Int., 44 (2004),
No. 11, 1787.

7) M. Bujrström, A. Tilliander, M. Iguchi and P. G. Jönsson: ISIJ Int., 46 (2006), No. 4, 523.

8) P. Ternstedt, A. Tilliander, P. G. Jönsson and M. Iguchi: ISIJ Int., 50 (2010), No. 5, 663.

9) A. Hiratsuka, T. Fujikawa, Y. Nasukawa, R. Tsujino and M. Iguchi: J. JSEM, 9 (2009), No. 3, 236.

10) M. Hashimoto, R. Tsujino, A. Hiratsuka, I. Awata, T. Fujikawa and M. Iguchi: J. JSEM, 8 (2008), No. 3, 206.

11) A. Hiratsuka, T. Fujikawa, Y. Nasukawa, R. Tsujino and M. Iguchi: J. JSEM, 9 (2009), No. 3, 236.

12) Y. Nasukawa, T. Fujikawa, R. Tsujino and M. Iguchi: Mater. Trans., 51 (2010), No. 9, 1560.

13) M. Iguchi, S. Hosohara, T. Kondoh, Y. Itoh and Z. Morita: Tetsu-toHagané, 79 (1993), No. 8, 934.

14) M. Iguchi, D. Iguchi, Y. Sasaki, T. Kumagai and S. Yokoya: ISIJ Int., 44 (2004), No. 10, 1623.

15) M. Iguchi, K. Nakamura and R. Tsujino: Metall. Mater. Trans. B, 29B (1998), 569. 